\title{
Dinámicas territoriales en asentamientos de pescadores artesanales: economías, experiencias y conflictos. El caso de Guabún y Puñihuil en la comuna de Ancud, Chiloé
}

\section{Territorial Dynamics in Small-Scale Fishing Villages: Economics, Experiences and Conflicts. The Case of Guabun and Puñibuil in the Ancud District, Chiloé}

FRANCISCO THER RÍOS

Universidad de Los Lagos, Osorno, Chile

JAIME VALDERRAMA BRAVO

Universidad de Los Lagos, Osorno, Chile

RESUMEN Las transformaciones socioeconómicas y ambientales de las caletas de pescadores, derivadas de la temprana inserción del sector en la economía internacional, se suman a diversos procesos de transición a la modernidad que afectan a las sociedades que habitan los espacios costeros, cambiando sus prácticas cotidianas. Un segundo factor lo constituye la creciente oferta turística en la franja costera que implica nuevas adaptaciones para los asentamientos de pescadores. Estos factores actúan sobre el borde costero generando procesos de desadaptación y desorientación en las comunidades de pescadores, lo que constituye un negativo factor tanto para el ordenamiento territorial como para la administración de recursos pesqueroartesanales. En este contexto, el artículo profundiza en las dinámicas territoriales presentes en dos localidades litorales de la Isla Grande de Chiloé, para lo cual se analizan los procesos económicos culturales y las temporalidades de los lugares de extracción de recursos pesquero-artesanales. Se trabaja con 
una metodología cualitativa utilizándose cartografía participativa y entrevistas en profundidad, además de una encuesta bioeconómica. El objetivo central es comprender desde un enfoque geosocial los procesos económicos y productivos en ambas caletas, junto a las posibles causas que generen conflictos. Finalmente, se presentan los fundamentos y aspiraciones que hacen de ambas localidades un foco de atención en el ámbito del desarrollo local en este tipo de actividades productivas.

PALABRAS CLAVE Desarrollo económico local, sociedades litorales, áreas de manejo y explotación de recursos bentónicos (AMERB), Chiloé.

ABSTRACT The socio-economic and environmental transformations undergone by fishing villages, as a result of the premature insertion of this sector into the international economy, come in addition to a variety of modernisation processes affecting the societies which inhabit coastal spaces, changing their daily lives. A second factor is the growing supply of tourism services along the coast, implying new adaptations for fishing settlements. These factors act on the coastline, generating processes of disadaptation and disorientation in fishing communities. This constitutes a negative factor both for territorial ordering and for the administration of the resources on which small-scale fishing depends. In this context, the article examines in greater depth the territorial dynamics present in two coastal communities on Chiloe Island, through analysis of the economic and cultural processes and the variations over time of the fishing grounds used by small-scale fishermen. A qualitative methodology is used, based on participative cartography and in-depth interviews, as well as a bio-economic survey. The central objective is to understand from a geosocial focus the economic and productive processes in the two villages, together with possible causes of conflict. Finally, we present the basic factors and aspirations which have made the two communities a focus of attention in the ambit of local development in this type of productive activity.

KEYWORDS Local economic development, coastal societies, areas for the management and exploitation of benthic resources (AMERB), Chiloé.

En la actualidad es importante avanzar en los desafios para la conservación, manejo de recursos marinos y ordenamiento territorial en los espacios litorales en Chile (caso ilustrativo de ello es la Agenda 2 I local; véase Díaz, 2008), más 
aun considerando los recientes sucesos, como el terremoto y tsunami ocurridos el 20 Io en Chile, que impactaron directamente los ambientes costeros del centro sur del país e implicaron un difícil comienzo de siglo xxi para el mundo pesquero artesanal. En estos desafíos la pesca artesanal es la actividad principal, en tanto tiene un papel esencial tanto en la economía como en el arraigo territorial de la población en el borde costero (Confepach, 2008). A las transformaciones socioculturales, medioambientales y productivistas del sector (García-Allut, 2003), derivadas de su inserción en un modelo de desarrollo exportador, se suman nuevos usos en tierra y mar, producto de una creciente oferta turística (MOP, 2006), principalmente abocada a las zonas de veraneo, paisajes marinos y la gastronomía local. El constante efecto de éstas y otras condiciones sobre la dimension espacial del litoral, se acompaña de una situacion de transición a la modernidad en diversas caletas de pescadores artesanales (Ther Ríos, 2008), donde las prácticas tradicionales coexisten con estos nuevos dominios. Lo anterior implica un manejo particular y cuidadoso del borde costero (Andrade, en Arenas y Cáceres, 200I), que exige a su vez un enfoque integrado sobre el litoral (Barragán, Alvarado y Castro, 2005). Al respecto, las actuales normativas, como por ejemplo la política de uso del borde costero iniciada en 1994 en el país, son propicias para emprender un avance hacia la inclusión de la complejidad territorial de las caletas de pescadores en los sistemas normativos. En dicho imperativo es importante considerar los asentamientos costeros como territorios vividos (Ther Ríos, 20I0), donde las dinámicas socioterritoriales y sus vinculaciones con las técnicas de ordenamiento territorial y de administración de recursos aparecen en las prácticas cotidianas del territorio. Con ello se permite elucidar desde la diversidad interna de los asentamientos, las variables y relaciones críticas que posibilitan la permanencia y desarrollo de los ambientes costeros.

En los espacios costeros donde históricamente han habitado pescadores artesanales, la cultura local es el principal mediatizador entre ellos y su entorno (Leff, I994). Los espacios de vida, social y vivido (Di Meo en, Lindón y Hiernaux, 2006) coexisten y constituyen a éstos como territorios resultantes de interacciones entre quienes viven en él (Aliste, 2008). En la zona costera, la confluencia de diversas racionalidades (Morin, 2008), atravesadas por verticalidades y horizontalidades en el espacio de vivencia (Santos, 2004), problematiza la direccionalidad de la gestión y ordenamiento. En efecto, la costa se presenta como un atractivo para actividades urbanas, rurales, industriales, acuícolas, comerciales, turísticas, de transporte, agrícolas, pesqueras, entre 
otras. Así es como en los asentamientos costeros del sur de Chile, los procesos tradicionales y modernos interactúan en diversas escalas espaciales tanto a nivel de poblaciones humanas (Hucke-Gaete, 2009a; 2009b), como a nivel de espacios y procesos marítimos (Molinet, Arevalo, Díaz y Díaz, 2008). Las principales instancias que entran en acción en el borde costero, con efectos probados sobre asentamientos de pescadores, son la Ley General de Pesca y Acuicultura (Henríquez Genotti, 20I0), la política de uso del borde costero (Ávalos Pino, 2006), aplicación de figuras de administración de recursos (Ceballos Cardona, 2009), desarrollo turístico (Zamora, Barril y Benavides, 2010) y las crecientes mercantilizaciones sobre ámbitos folclóricos y costumbristas de los territorios (Carenzo, 2007). Es relevante señalar que las figuras de administración de recursos corresponden a dos: las áreas de manejo y explotación de recursos bentónicos (AMERB) y las concesiones de acuicultura. A ello se suma el sistema de áreas marinas protegidas administrado por la Subsecretaría de Pesca.

En particular estos condicionantes influyen de diversas formas sobre los asentamientos costeros. Los ámbitos que expresan con claridad un efecto en las caletas de pescadores son las pautas esquemáticas y las maquinarias productivas, sostenidas por la ciencia, para la explotación local de recursos, la creciente demanda de especies por parte del mercado internacional y el Estado, que implementa y hace cumplir las normativas mediante instituciones sectoriales. En efecto, la introducción acelerada de ajustes científico-técnicos, implícitos en la normativa legal y en las tecnologías productivas, interviene y desorienta la compleja vinculación hombre-medio, que sostiene gran parte de la actividad pesquero-artesanal (Frezza, I988). La presión sobre los recursos naturales costeros, derivada de una política de exportación (Rojas, 2004; Moreno, 2006) genera constantes migraciones, reorientaciones y especializaciones productivas en los sistemas locales (Henríquez Genotti, 2010). Por su parte, los cambios legales enfatizan excesivamente la productividad extractiva especializada dejando de lado consideraciones básicas de sustentabilidad concernientes al dominio sociocultural del borde costero (FDLA, en Ávalos Pino, 2006). La dirección de este conjunto de normativas, a parte de ser repentina, no es clara y consensuada. Provenientes desde la racionalidad científica y con intereses de gobernar desde arriba, su dirección no responde a la relación entre sociedad y naturaleza que expresan los modos de vida en los diferentes territorios litorales. Su principal efecto y consecuencia es que introducen incertidumbre en el entorno de los pescadores disminuyendo su posibilidad de gestionar tanto el territorio como los recursos. Desde el otro lado (arriba) se observa 
que a largo plazo dicha situación se vuelve negativa, debido a que las políticas sociales de ordenamiento territorial o manejo de recursos costeros no motivan a los pescadores. Todo ello va constituyendo un círculo vicioso que actúa finalmente en contra de ambos, al acabar con las posibilidades y capacidades que necesitan los asentamientos costeros para construir el futuro del sector.

En todo caso, estas disparidades pueden producir conflictos territoriales (Andrade, Arenas y Guijón, 2008) o pueden generar complementación y cooperación (Montañez y Delgado, I998). En consideracion de esto, el objetivo de la presente investigacion está en dilucidar variables críticas que permitan discernir planteamientos sobre ordenamiento del borde costero y administración de recursos marinos, a partir de la descripción y comparación de dinámicas socioterritoriales en las áreas de manejo y explotación de recursos bentónicos (AMERB) en dos asentamientos costeros ubicados en el borde noroeste de la isla de Chiloé. El caso de las Amerb es ilustrativo al respecto por tres motivos: i) pues son figuras de administración pesquero-artesanal que conciernen tanto al ordenamiento territorial como a la administración de recursos bentónicos (Barragán, Alvarado y Castro, 2005); en ellas se conjugan la territorialidad para los recursos y normatividad para su extracción, por tanto permiten el estudio de ambos aspectos en la práctica; ii) en las AMERB las normas territoriales y sectoriales se mezclan con el entorno histórico-cultural de las personas, lo cual permite profundizar el uso de la figura a través de la cultura local, enfocando su complementación con las prácticas productivas de los pescadores (Stotz, I997); iii) los órdenes y esquemas en que se desenvuelven las variables dentro de las AMERB, se presentan como pequeños focos que ilustran las problemáticas y soluciones posibles de alcanzar considerando otras figuras, sectores costeros regionales y, en una escala mayor, el propio borde costero.

\section{Transformaciones de la pesca artesanal: de la cultura a los territorios costeros de Chiloé}

El sector de la pesca artesanal en Chile se puede entender a partir de tres momentos: i) una conformación cultural de la pesca artesanal anterior a la apertura económica (antes de I973); ii) cambios productivos, técnicos y legislativos derivados de la apertura económica y sobreexplotación de diversas especies (I973-I980-I990); y iii) regulación de la extracción de recursos (I990-20IO).

En la mirada donde la cultura chilota es el todo y las prácticas pesqueroartesanales son las partes, también se puede decir que cada práctica es un todo 
en el ambiente, y por tanto en ellas se expresan los vértices culturales de la madera, el mar y el campo. Esta conformación cultural está presente con mayor intensidad en el mar interior, producto de que fue éste el epicentro de colonización y posterior surgimiento de la cultura chilota, pero no se agota hacia el borde costero occidental. En efecto, al ir desde el continente hacia la comuna de Ancud, o cruzar desde mar interior hacia mar exterior bordeando el canal del Chacao, el océano Pacífico es también una apropiación sociocultural de los chilotes; es una continuidad entre el mar interior y el mar exterior.

Las prácticas pesquero-artesanales en Chiloé comienzan sus transformaciones desde antes de la apertura económica. Sin embargo, debido a su arraigo de fuertes vínculos en las dimensiones ambientales del territorio insular, muchas de ellas se han mantenido hasta la actualidad en las caletas de pescadores. Allí se organizan en torno a los ambientes entre tierra-costa-mar, y cada práctica expresa todos los vértices de la cultura chilota de forma hologramática (Lindon, 2007). El primer vértice es la cultura marítima cuya configuración radica en la importancia del mar como aquel centro que, además de ser reservorio de la mitología isleña, provee el recurso para sostener un modo de producción ligado a un modo de vida pesquero-artesanal (Grenier, I984). La cultura de la madera (Marino y Bianchi, I980), donde los bosques milenarios, principalmente de alerce y ciprés, han dado origen a estilos de vida, historias de pertenencia, prácticas productivas y elaboraciones en madera, propias de una arquitectura distintiva. La cultura campesina está conformada principalmente por dos ámbitos; la minga (Cárdenas, en Bravo Sánchez, 2004), que aún contituye un núcleo de reciprocidad y sistema de trabajo presente en caletas de pescadores, y la papa, cuya importancia se debe no sólo a la diversidad de especies que presenta la isla, sino también a que es un sustento cotidiano y un valor patrimonial (Negrón, I992; Santana, I998). A ello se suma la relación que establecen los grupos humanos que, siempre buscando salida al mar y conexión hacia el interior terrestre, constituyeron una relación bordemarina (Bravo Sánchez, 2004) expresada en los pueblos y ciudades adaptados a ambos ambientes.

Entre I 820 y I 880 se produce la instalación de empresas exportadoras y de procesamiento en Chiloé. Principalmente locos (Concholepas concholepas), lapas (Fissurella spp), cholgas (Aulacomya ater) y tacas (Protothaca thaca), entre otros, eran cosechados en Chiloé y desde allí compañías inglesas y francesas comercializaban hacia el norte. Mientras se instalaban las primeras empresas conserveras en Calbuco, en la isla Quiriquina el choro zapato (Choromytilus 
chorus) ya se presentaba en situación de sobreexplotación. En I 890 comienza el enlatado de róbalo, pejerrey y erizo, y los monopolios de precios se hacían notar por el alto precio de algunos recursos como la ostra (Couyoumdjian, 2009). Contrario a una naturaleza intrínseca, proveniente de un condicionamiento originario dado por un modo de producción depredador, los modos de extracción del pescador artesanal son dinámicos y responden al contexto económico global donde se insertan (Andriguetto-Filho, 1999). No son las técnicas de los pescadores, sino las relaciones entre comunidades, intermediarios y empresas, las que desatan las sobreexplotaciones. Es de esperar que con la introducción de mayor cantidad de demandas de recursos, los sistemas de prácticas de los asentamientos locales (caletas de pescadores) se sobreexijan, generando cambios repentinos en las técnicas. Así es como en algún momento las familias chilotas comienzan a orientar su producción más allá de su propia alimentación y del comercio local:

Se espera una de las grandes mareas; se marisca en las bancadas naturales, según las especies que más agraden al consumidor; se lavan las conchas, despojándolas de todo objeto extraño y se trasladan en seguida a la playa donde debe hacerse el cholcheñ. Calculando el nivel de las mareas chicas, se depositan los moluscos, según sus especies, en grupos separados, extendiéndolos sobre la playa sin recargarlos, para evitar la asfixia. Quedan, pues, así en un plano emergente, en donde el flujo y reflujo y el curso de las corrientes limpian el molusco, que engorda y adquiere un sabor más agradable (Maldonado, en Couyoumdjian, 2009).

Lo anterior deja ver cómo se orienta el sentido de las prácticas cuantitativa y cualitativamente hacia la producción para otros dominios fuera de las necesidades tradicionales. De ahora en adelante, no se extrae la cantidad que el contexto económico endógeno y las costumbres de alimentación local requieren, sino que se extrae según lo que más le agrade al consumidor y en la mayor cantidad posible. Hacia fines del siglo xix los territorios litorales se transformaron en sectores productivos para el comercio de productos del mar, dejando de lado el mundo tradicional que confirmaba un legítimo modo de vida costero, al ser valorados por lo principal que dominaba en aquellos tiempos: la economía de la extracción de recursos con fines de ganancia económica industrial, la cual hoy por hoy revaloriza con el mismo afán en la cultura local, exponiendo sus costumbres como mercancías para el turismo global, dejando de lado aho- 
ra todas aquellas dimensiones borradas por la homogeneización, tales como las características ecológicas y el sentido local dado a las prácticas, el carácter más profundo de las costumbres entendidas como direcciones de desarrollo distintas a la planificación, entre otras. Aquello genera una sobrexplotación inicial de recursos con el agotamiento de bancos naturales en algunos sectores de la isla, con algunos bancos de recursos agotados. Los síntomas de lo que sería la gran sobreexplotación de la segunda mitad del siglo xx, basada en fiebres y booms económicos de recursos, que continúa creciendo hasta nuestros días.

No se molestan en lavar las conchas al levantarlas con la rastra, llegan al mercado y aún hasta las provincias centrales con una masa de fango, que asfixia al molusco, cuando no le comunica un hedor insoportable. Como consecuencia, las ostras del día desmerecen mucho en el mercado, con perjuicio de la industria y de los consumidores. [...] sin observar método alguno, ejercían su oficio tan torpemente que han concluido por esterilizar los bancales naturales. No pensaban, como ahora no piensan, en el porvenir y rastreaban sin conmiseración; elegían las conchas que apetecían, arrojando en seguida al agua los escombros que había levantado la rastra, y con tan absurdo procedimiento, terminaron por ahogar al molusco, que ha perecido por asfixia (Maldonado, en Couyoumdjian, 2009).

Y mientras que - como se expresa en la cita- la significación de este momento es atribuida al carácter del recolector chilote que no sabe cómo trabajar, la ola de cambios continua y esta ignorancia se mantiene hasta bien entrado el siglo xx e inaugura el periodo propio de la modernización de la pesca artesanal. Donde el propio conocimiento local del pescador no es apto ni suficiente para convertirlo en un administrador de recursos. En este segundo periodo se inicia una apertura económica del sector pesquero donde «las políticas de libre acceso, fomento a las exportaciones y desregulación, incentivaron la inversión de capitales para estimular una expansión de la actividad productiva» (Camus y Hajek, I998). La economía exportadora en el país genera una serie de aumentos de precio para los recursos; primero para recursos bentónicos como el loco (Concholepas concholepas), demersales como la merluza (Merluccius australis) y luego para las algas como el pelillo (Gracilaria spp) y la luga (Iradaea spp). Desde la apertura económica de los recursos pesqueros, antes de las actuales regulaciones institucionales, la actividad presentaba características trashumantes (Retamales y Álamos, 20I0), en tanto implicaba un seguimiento 
por diversos sectores marítimos hacia las especies para su captura. Los pescadores se movilizaban hacia el sur en busca de recursos de alto valor, como el loco (Concholepas concholepas) y la merluza austral (Merluccius australis). Al momento de la llegada de los pescadores se producían diversos conflictos, como la incorporación de nuevas prácticas de extracción con redes, anunciadas como dañinas por los medios de comunicación local (Curumilla, 2006). Más tarde, estas migraciones norte-sur, fueron generando fenómenos socioculturales y económicos que reconfiguraron territorialmente caletas artesanales, conformando diversidades internas que se mantienen hasta la actualidad en algunas de ellas (Gajardo y Ther Ríos, 20II).

Para el ordenamiento institucional del sector, la Ley General de Pesca y Acuicultura nro. I 8.892 (I989) y sus modificaciones (I99I), distingue tres tipos de actividades extractivas; la pesca, el buceo y la recolección de orilla, las cuales podían ser realizadas por un mismo pescador. Por otra parte, se puso fin al nomadismo mediante la restricción de que todas las prácticas realizadas deben ser en la región donde se registra formalmente como pescador artesanal (Gobierno de Chile, 2007) y se dio origen a las concesiones acuícolas, lo que inicia una problemática historia con la salmonicultura influyendo en las caletas de dos maneras: tanto por la contaminación de los fondos marinos (Saavedra, 2008), como atrayendo a los buzos mariscadores a los centros industriales en precarias condiciones laborales y generando, a la vez, negativos procesos de asalarizacion en los centros salmoneros y de desterritorializacion de las caletas de pescadores. El periodo de regulación tiene influencia sobre dinámicas socioproductivas cotidianas como, por ejemplo, la aplicación de nuevos sistemas de administración pesquera, los que insisten en el sedentarismo e impulsan la creación de organizaciones de pescadores a cargo de sectores marítimos, con el objetivo de ir hacia una actividad sustentable. Posteriormente, en I994 se origina la primera Política Nacional de Uso del Borde Costero, que junto con otras normativas ejercen efectos diversos, principalmente en forma de conflictos por las distintas estrategias entre grupos indígenas y no indígenas respecto a los territorios costeros (Reyes y Jara, 2005; Guerra y Skewes, 2010). En I995, la lógica sedentaria de la productividad pesquero-artesanal, se consolida con las AMERB (Ley 19.492, artículo único, letra a). Éstas consisten en entregar un sector marino a una organización de pescadores para que ellos, con la asesoría de un organismo técnico-científico, hagan uso ordenado de los recursos bentónicos en un proceso que a largo plazo iría «manteniendo los stocks naturales mediante el comanejo y la explotación racional de los mismos» (Gobierno de 


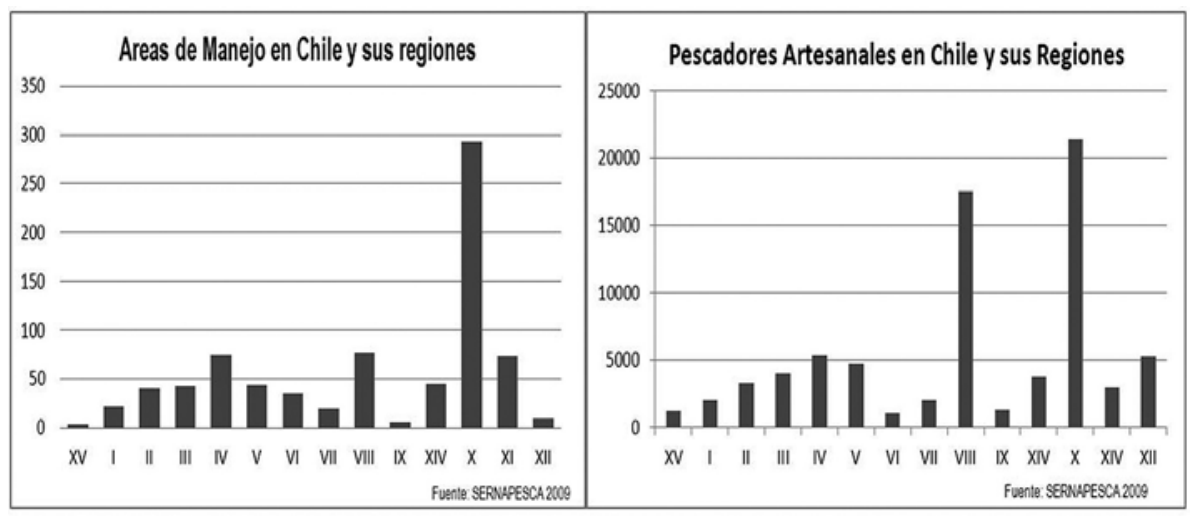

Figura 1. Situación de pesquería artesanal en Chile (AMERB y R.P.A)

Chile, 2007). En la actualidad existen un total de 780 AMERB, distribuidas en las 5 regiones de Chile (figura I), las cuales fueron concesionadas y entregadas recientemente en los últimos io años (Sernapesca, 2009).

Con ello se lograba ordenar espacialmente a los pescadores mediante la sedentarización de sus prácticas, organizacionalmente mediante la sindicalización y ambientalmente mediante la reproducción controlada de las especies dentro del área, todo lo cual se esperaba avanzaría en lograr un desarrollo sustentable de la actividad. Dichas normativas persisten hasta la actualidad y junto a los efectos del mercado, son la huella de diversos cambios en las estrategias adaptativas de las comunidades costeras (Tamayo Quilodrán, 2007), de manera que en algunas comunidades se instalaron intereses como el obtener una mayor extracción de recursos o surgieron intereses turísticos, mientras otras demandan estrategias de conservación de la biodiversidad (Cox Fernández, 2007).

\section{Área de estudio: caletas de Guabún y Puñihuil en el borde costero occidental de Chiloé}

Los asentamientos que se consideran en la presente investigación corresponden a las caletas de Guabún y Puñihuil, ambas se ubican en el borde costero occidental de la isla.

En el sector de Puñihuil existe una presencia de habitantes provenientes del norte del país, lo cual marca el estilo de vida social, actividad económica y condiciona el uso del área de manejo. Este sector ha sufrido fuertemente la influencia del pescador nómada. Hacia I985, durante la «fiebre del loco», se 

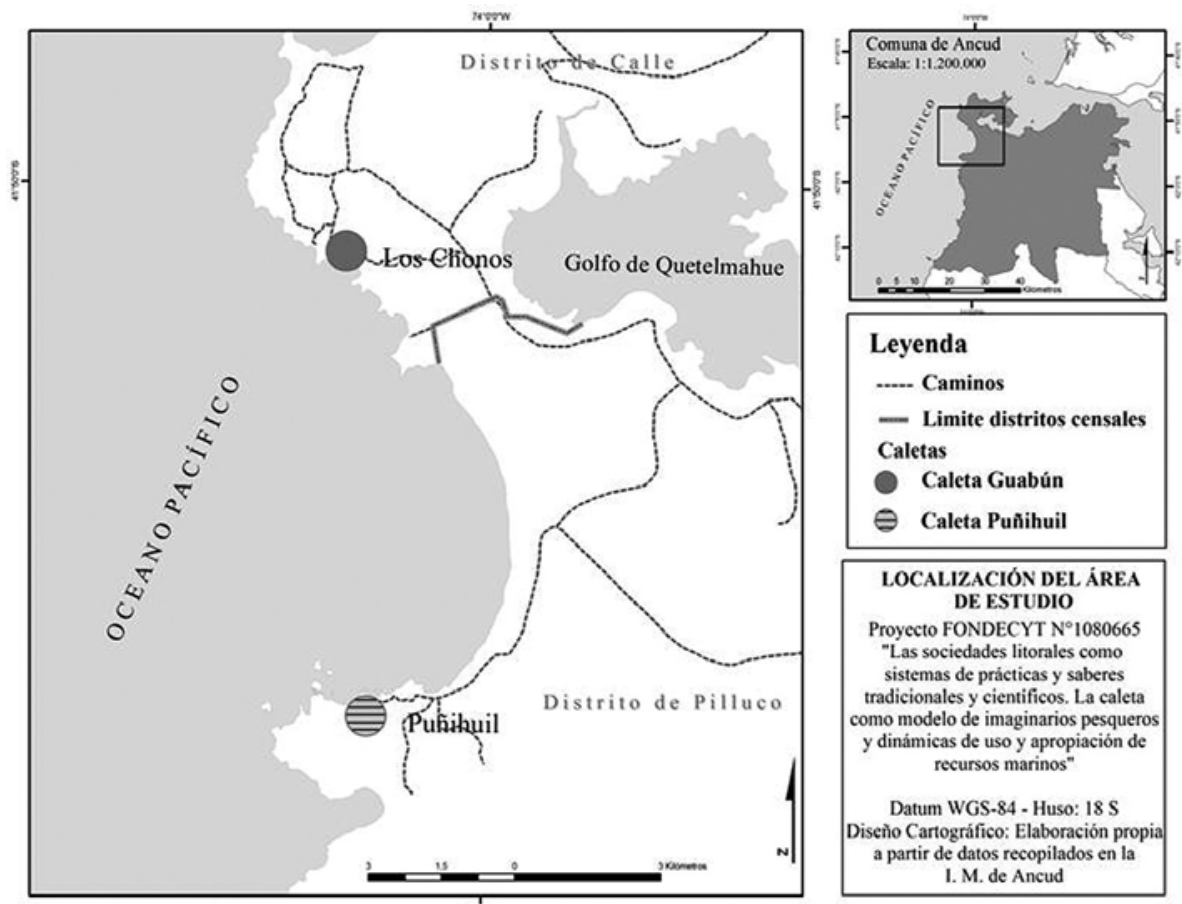

Figura 2. Área de estudio. Caletas de Guabún y Puñihuil en el borde occidental de la isla de Chiloé.

generó una migración masiva desde la zona norte del país; principalmente de Los Vilos y Constitución con dirección a Chiloé y otros sectores del sur austral. A partir de la exigencia implícita en las figuras administrativas que regulan la pesca artesanal (Ley General de Pesca y Acuicultura, I99I), los pescadores ya asentados tanto en la bahía como también en Ancud formaron el Sindicato de Pescadores Artesanales «Viento Fuerte» de Puñihuil, solicitando un Amerb el año 2002. En ella realizan la extracción y el cuidado del recurso loco, complementariamente a la extracción de corvina (Cilus gilbertison) y mantarraya (Manta birostris), ambos extraídos en el periodo estival. La actividad del área de manejo es estacionaria (Junio-Agosto), y funciona mediante procesos de repartición del trabajo entre la totalidad de los socios del sindicato a cargo (la repartición se hace en base a la cuota asignada anualmente por la Consultora Prisma y es en partes iguales). La actividad turística es la cara visible de la caleta y es una actividad económicamente relevante, debido al gran impacto mediático y coyuntural relacionado con la conservación de la biodiversidad. En efecto, los tres islotes ubicados a poca distancia de la costa han sido objeto 
de estudio de fundaciones e instituciones con fines de conservación (Conaf, Fundación Ottway). Esto se debe a que durante los meses de septiembre a abril se produce la llegada de colonias mixtas del pingüino Humboldt (Spheniscus humboldti) y magallánico (Spheniscus magellanicus), además de mamíferos marinos como el chungungo (Lontra felina) y el lobo marino (Otaria flavescens), entre otros. A partir de este atractivo se intentó fomentar el turismo creando asociaciones entre pescadores, instituciones y organismos no gubernamentales, donde el periodo de rentabilidad está determinado por el tiempo en que los pingüinos se mantienen en el sector, ya que durante este periodo ambas especies construyen una cueva de unos 50 centímetros donde depositan dos huevos. La incubación de estos huevos toma unos 38 a 42 días, después de los cuales los padres alimentan a los polluelos hasta los 80 días de nacidos. Una vez que los pollos desarrollan plumas apropiadas para la vida en el agua, los adultos dejan de alimentarlos y estos últimos comienzan la muda anual. Estas organizaciones locales, además de realizar circuitos guiados a los sectores donde se avistan los pingüinos (monumento natural Islotes de Puñihuil), también cuentan con un servicio gastronómico especializado con dos restoranes en la bahía (Bahía Puñihuil y El Rincón) con comidas típicas de la zona y una recepción personalizada al turista extranjero. Como última actividad productiva (ya a menor escala), existe un kiosco de bebidas y confites, además de la venta de artesanías en la orilla de la playa.

En la localidad de Guabún, el habitante chilote reconvirtió su forma habitual de trabajo ligada a la agricultura, extendiendo su sistema de prácticas hacia el mar como parte de una estrategia adaptativa presente en las comunidades cercanas (Tamayo Quilodrán, 2007). Aquí el impacto de las transformaciones de la pesca artesanal no ha afectado de igual manera que en Puñihuil, puesto que los modos de vida de sus habitantes evidencian una cultura típica del chilote tradicional. Desde épocas anteriores, la mayoría de la población residente ha trabajado en la agricultura como principal fuente de ingresos. En general, el sistema productivo de Guabún se aplica a un ambiente costero que, a la vez, es uno campesino. La vida cotidiana del pescador artesanal de Guabún transcurre entre estos espacios. La unidad familiar en la caleta de Guabún distribuye sus quehaceres entre el espacio tierra-mar. Asociados a los factores geográficos en este sector, las principales actividades pesqueras son el marisqueo de orilla, el marisqueo en profundidad y la recolección de orilla. Los habitantes de Guabún consideran cuatro sectores: el primer sector es el mar profundo, que no es utilizado por los pescadores de Guabún, pero se 
sabe que es utilizado por pescadores de otras caletas para extraer recursos. En el extremo opuesto está la orilla que es el sector de arena despejada de agua (playa) utilizado para la recolección de algas. Unos metros más adentro esta el sector de las rocas golpeadas por las olas con mayores y menores intensidades que es utilizado para extraer mariscos. Luego el sector de bajas profundidades que posibilitan seguir la norma de los 20 metros para el buceo utilizado para el marisqueo en profundidad. A partir de la década de ı980, hubo un mayor impulso a la pesca bentónica, extrayendo principalmente almejas (Diplodon chilensis), erizos de mar (Tetrapygus niger), piure (Pyura chilensi) y algunas algas como luga (Gigartina skottsbergii) y pelillo (Gracilaria spp). De esta actividad surgió el sindicato «Los Chonos de Guabún», el cual abogó por la creación de una AMERB. Fue así como a partir de las nuevas figuras administrativas decretadas en la Ley General de Pesca y Acuicultura de I99I se logró conseguir este espacio, el cual desde el año 2002 ha trabajado con el recurso loco. Este caso es relevante, principalmente por el éxito económico que han alcanzado hasta el día de hoy, aunque la cantidad de extracción es menor a la de Puñihuil, la calidad y el tamaño del recurso es ampliamente superior, lo cual refleja el cuidado y visión de sustentabilidad por parte de la sólida organización sindical de sus habitantes, como base productiva que involucra sus costumbres con los usos de la figura administrativa. Proporcionalmente la cantidad del recurso loco es superior en Puñihuil, sin embargo por una extracción masiva (350.000 unidades al año 2008) los tamaños son inferiores, lo cual implica una baja en el precio de compra ( 450 pesos por unidad), equivalente a 0,74 dólares la unidad (un dólar equivale a 606 pesos, según valor del dólar observado para febrero de 2009, mes del trabajo de campo; véase SII, 2009).

\section{Metodología}

\section{Materiales y métodos}

La metodología y tratamiento de la información estuvo basada en un enfoque cualitativo no experimental, entendido como una constante relación «mantenida entre teoría y método, y entre teoría y terreno donde el objeto científico se construye desde abajo y a lo largo de la investigación, cuyo principal objetivo está en el descubrimiento y la emergencia de conocimiento nuevo» (Santana, 2003, en Ther Ríos, 2003).

La estrategia de muestreo consistió en recoger información entre los meses 
de febrero y mayo del año 2009 en los sectores de Guabún y caleta Puñihuil; el proceso se realizó siguiendo la técnica de los informantes clave y considerando un tamaño muestral según el criterio de saturación de la información (Valles, 1997). Los informantes clave para el desarrollo de este estudio fueron los habitantes de las localidades, junto con los dirigentes de cada una de las organizaciones que formaban parte del territorio en cuestión. Se hizo especial énfasis en los presidentes de los sindicatos debido a su importancia actual en las caletas de pescadores (Chandía, 2008), en particular debido a que aquello permite ingresar a la realidad a investigar, respetando las jerarquías locales de autoridad, en este caso, de la principal organización del sector, lo cual establece desde el comienzo una relación de confianza (Rapport) entre el investigador y la comunidad (Ballesteros, 2006). Es así como fueron considerados como actores clave el presidente del sindicato «Los Chonos de Guabún», don Pedro Pino, y al presidente del sindicato «Viento Fuerte», don Ciro Cárdenas. A partir del criterio de cada presidente, sobre posibles conocedores de las prácticas en el territorio, sus características socioeconómicas y las técnicas implícitas en ellas, se siguió la recomendación de cada informante para encontrar al próximo. Considerando la existencia de un cierto conocimiento local respecto de las personas con mayor acumulación de experiencia, se adaptó la vía de entrada jerárquica anterior, con la técnica de la bola de nieve (Pulido-Rodríguez, Ballén-Ariza y Zúñiga-López, 2007). De las derivaciones y contactos surgidos de cada uno de los procesos, las entrevistas en profundidad se extendieron hacia las redes de los miembros del sindicato en Guabún y a las de agrupaciones turísticas en el caso de Puñihuil, constituyendo muestras heterogéneas de cada sector.

En cuanto a los instrumentos, se diseñó y aplicó una encuesta bioeconómica a partir de la cual se buscó entender las distintas relaciones que llegan a darse debido al impacto de la acción humana en la naturaleza. La información recopilada abordó los siguientes ámbitos: i) recursos que se explotan, ya sean ligados a la pesca artesanal como al turismo; ii) técnicas de captura y artes de pesca; iii) forma de comercializar los recursos; iv) costos asociados; v) sistema de organización y figuras administrativas; vi) visión y modos de vida. En un segundo trabajo en terreno, se realizaron entrevistas en profundidad (Taylor \& Bogdan, I998), basando su definición como una interacción cara a cara en busca de las perspectivas del informante, sus experiencias y vivencias en el territorio. Las entrevistas fueron previamente concertadas e improvisadas y su temática se guió mediante una pauta semiestructurada para conocer y 
caracterizar los factores económicos y culturales de los habitantes. También fue de importancia contar con el apoyo y disposición de los organismos públicos y privados, quienes contaban con amplios datos estructurales y de organizaciones, además del contexto institucional que regula normativamente el desarrollo local de cada sector tratado. La información primaria se contrastó con información secundaria recogida a través de revisión bibliográfica. Este ámbito se dividió en la revisión de una serie de publicaciones relacionadas con la pesca artesanal, con la finalidad de situar el actual contexto de la realidad estudiada y, en segundo lugar, en el caso de las AMERB se obtuvo información de Sernapesca, Subpesca, I. Municipalidad de Ancud, Gobierno Regional de la la Décima Región, junto con los talleres realizados en el Ceder conforme a los lineamientos del proyecto Fondecyt Io80665 y consultas al equipo de investigación. De esta manera la recopilación presentó una mayor certeza, dado que al ser contrastada con otras fuentes de información tendieron a optimizar los resultados. Finalmente para conocer las experiencias compartidas se llevaron a cabo talleres de cartografía participativa, entendida como un complemento a la encuesta y entrevistas realizadas.

Para expresar cartográficamente los resultados entregados en las entrevistas sobre la ubicación y situación actual de las AMERB, fue utilizado el software ArcGis 9.3 elaborando un mapa para cada localidad, a partir del cual se encontraron los factores socioculturales que se manifiestan en ambos territorios. También se evidenció la articulación de la economía local y las principales dinámicas que hacen a estos escenarios potencialmente conflictivos entre ellos. Esto se realizó considerando que estas formas de interpretación de datos influyen en quienes toman parte, en la naturaleza de los resultados y en las relaciones de poder (Chambers, 2005). La información cartográfica está representada a una escala de I:370.000 (nivel comunal), I:45.000 (las dos localidades).

\section{Resultados}

Dada la interactiva relación entre estas dos caletas, se hace indispensable detallar las realidades encontradas para luego llegar a un punto de encuentro o conflicto que logre explicar el porqué de las dinámicas existentes, y cómo actúan frente a la inminente actividad de desarrollo productivo en cada localidad. 


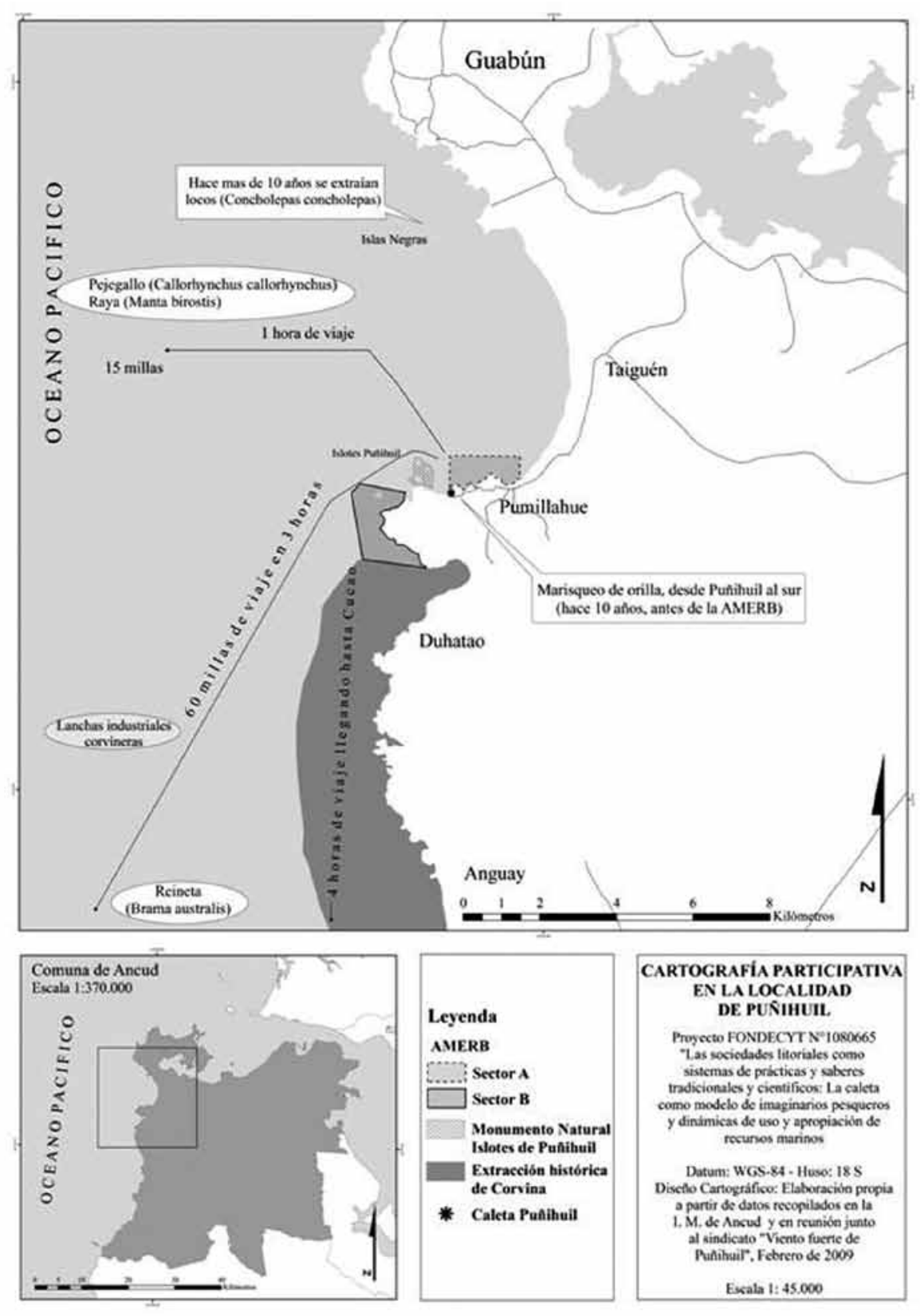

Figura 3. Cartografía participativa en la localidad de Puñihuil 


\section{Dinámicas socioterritoriales en Puñihuil}

Como se observa en la figura 3 , las prácticas que conforman los usos del espacio están distribuidas en un radio exterior al sector de playa y en un límite interior determinado por las AMERB y sectores de turismo. En círculos concéntricos, el radio exterior corresponde a las dinámicas de pesca demersal, las cuales no se agotan en la figura ni en determinados sectores representados; los trayectos realizados en este ámbito están en constante recreación a partir del movimiento de peces y el aprendizaje de nuevos sectores. El radio intermedio corresponde a las actividades de AMERB y viaje hacia las pingüineras. Ambas trayectorias coinciden en algunos sectores quedando yuxtapuestas las AMERB y la zona de los islotes en el espacio marítimo. A consecuencia de ello, los pescadores realizan actividades en zonas donde sea menos visible la extracción de recursos para el turista. En un radio central se divide el espacio entre las prácticas de residencia de los pescadores y los restaurantes abocados al turismo. Este espacio de la playa se encuentra fragmentado toda vez que la mitad de la playa es del turismo y la otra mitad es para guardar los botes y tener las ranchas.

En este sentido, Puñihuil se presenta como una caleta artesanal con potenciales de desarrollo y sujeta a una tensión interna por el aumento, en direcciones opuestas, de actividades turísticas y pesquero-artesanales. En efecto, por una parte el turismo apunta a sacar provecho de la belleza natural del lugar con sus instalaciones de restaurantes con vista al mar y los viajes a los islotes. Por otra, la pesca artesanal tiene su objeto en obtener el máximo provecho económico de los recursos tanto en el área de manejo de locos, como en las jornadas de pesca que se realizan mar adentro. Si bien el turismo diversifica el trabajo del pescador artesanal, esto es sólo al inicio ya que en la actualidad han llegado personas de fuera a explotar turísticamente la zona, lo cual ha dado origen a organizaciones en torno a la actividad. Esto ha desencadenado conflictos de territorialidad y el arraigo por parte de aquellos habitantes originarios, que valoran al turismo como la principal y más lucrativa actividad económica local. En el año 2000, las actividades de pesca (demersal y bentónica) y el turismo manifestaron su incompatibilidad dando origen a un conflicto entre la organización de pescadores y la fundación Ottway, que, entre otras cosas, denunció un abuso por parte de los pescadores en el uso de sus artes de pesca, las que invadían directamente los ecosistemas históricamente asentados.

Las dinámicas territoriales internas se conforman tomando como eje el AMERB. Desde el año 2002 coexisten dos áreas concesionadas para la extrac- 
ción de diversos recursos bentónicos, con el loco como especie principal. En Puñihuil el AMERB se divide en dos sectores, creados el año 2002 mediante el decreto nro. 966, contando con una extensión aproximada de 328 hectáreas. Para el 2008 se extrajeron 350.000 aprox., para el 2009 se aprobaron 43 I.000 aprox. Durante el 2009 el precio fue de 3.200 pesos por kilo. En el año 20 Io el primer sector aprobó su sexto informe de seguimiento y el segundo sector su séptimo informe. El sindicato a cargo de ellas «Viento Fuerte» de Puñihuil cuenta con 68 miembros, de los cuales 30 se dedican directamente a las labores de buceo trabajando en 20 embarcaciones. El trabajo lo realizan durante io a I 5 días, logrando la extracción total de la cuota asignada. Existe un marcado desinterés en el cuidado del AMERB, ya que sólo se puede trabajar en un par de meses durante el periodo invernal. Es por esto que como agrupación desembolsan grandes sumas de dinero para el cuidado y vigilancia anual de las áreas. Muchos de los socios trabajan en otros rubros domiciliados en sectores distanciados de la caleta y sólo llegan a trabajar en la temporada de cosecha (extracción del recurso), es en ese momento cuando se distribuyen las labores con un sistema organizado rígidamente.

El territorio efectivo de los pescadores está constituido por las 60 millas de viaje hacia el sur de la caleta y las I 5 millas mar adentro. La especie objetivo de captura es la corvina (Cilus gilberti, con un precio de I.500 pesos por kilo, equivalente a 2,5 dólares aproximadamente), además de otras especies acompañantes, como la mantarraya (Manta birostris, con un precio de I.000 pesos por kilo, equivalente a I,6 dólares aproximadamente) y el pejegallo (Callorbynchus callorhynchus, con un precio de 500 pesos por kilo, equivalente a 8,8 dólares aproximadamente). Como artes de pesca son utilizadas las redes y los espineles, además de esto muchas embarcaciones cuentan con un motor capaz de levantar las redes del fondo, denominado «reductor», el cual fue traído desde el norte del país (Constitución, región del Maule). Junto a estas especies se agregan a la captura la centolla (Lithodes antarcticus), la jaiba (Callinectes sapidus), la almeja (Protothaca thaca) y el piure (Pyura chilensis); solamente el lenguado (Paralichthys adpersus) es descartado y devuelto al mar. Se trabaja 5 días a la semana durante el periodo estival, en invierno todo se condiciona por las intemperancias climáticas, aunque durante esos meses se trabaja en otras localidades. La manera de encontrar cardúmenes consiste en seguir el rumbo de ballenas azules (Balaenoptera musculus) y lobos marinos (Otaria flavescens) que se avistan en las cercanías de la caleta. El desembarque y venta se produce en la playa, directamente a tres intermediarios que visitan el sector. 
La complejidad de los usos del espacio se puede ver considerando la coexistencia de las diversas actividades y las valoraciones sobre ellas. Allí el turismo ha logrado incorporar el trabajo del pescador artesanal en conjunto con la organización de un grupo de habitantes originarios de la caleta; esto queda demostrado al momento de visitar y ver como se han ido creando una serie de construcciones destinadas al equipamiento comercial, las que ofrecen un servicio gastronómico complementario al circuito de recorrido mar adentro, en donde la gente logra observar la fauna existente en la zona (turismo de observación) con una duración de 30 minutos por un precio de 4.000 pesos. Es así como ya se han creado agrupaciones que buscan un desarrollo sustentable de esta localidad, considerando las ventajas comparativas que presenta junto con la gran afluencia de visitantes extranjeros (las ganancias así lo confirman, ya que para el periodo 2007-2008 operaron seis embarcaciones, divididas en dos agrupaciones turísticas unidas por lazos sanguíneos — primos, hermanos, matrimonios-, con un total de ingresos superior a los 70 millones de pesos). En este caso los procesos económicos giran con más fuerza a partir del turismo local, caracterizado por ser exclusivamente escénico. Sin embargo, aún se mantienen los sectores históricos de extracción además, de las AMERB concesionadas desde el año 2002 a la fecha. Esto ha llegado a ser un foco de conflicto entre los habitantes originarios o cercanos a la zona versus los pescadores provenientes del norte del país.

\section{Dinámicas socioterritoriales en Guabún}

Las dinámicas socioterritoriales de la caleta de Guabún se distribuyen en la costa y tierra firme delimitando un espacio costero retraído hacia el interior. El territorio efectivo de esta caleta, es decir, el territorio coincidente con el mapa mental de los pescadores, incluye trayectorias que conectan los espacios terrestres y costeros, en donde las costas delimitan zonas de poca profundidad marítima. Un ejemplo de ello es que en el año calendario, los pescadores de Guabún cambian sus botes de lugar; éste sería un movimiento fundamental para entender las prácticas de mar. Cuando llegan los meses en que dura la cosecha de locos, los botes son trasladados por días o semanas desde cada sector familiar, hasta la playa Los Chonos donde se ubica al área de manejo. Cuando la cosecha de locos o las actividades de limpieza se termina, los botes son trasladados nuevamente hacia cada sector marino frente a los hogares, donde siguen trabajando en varias actividades; al presentarse las actividades 


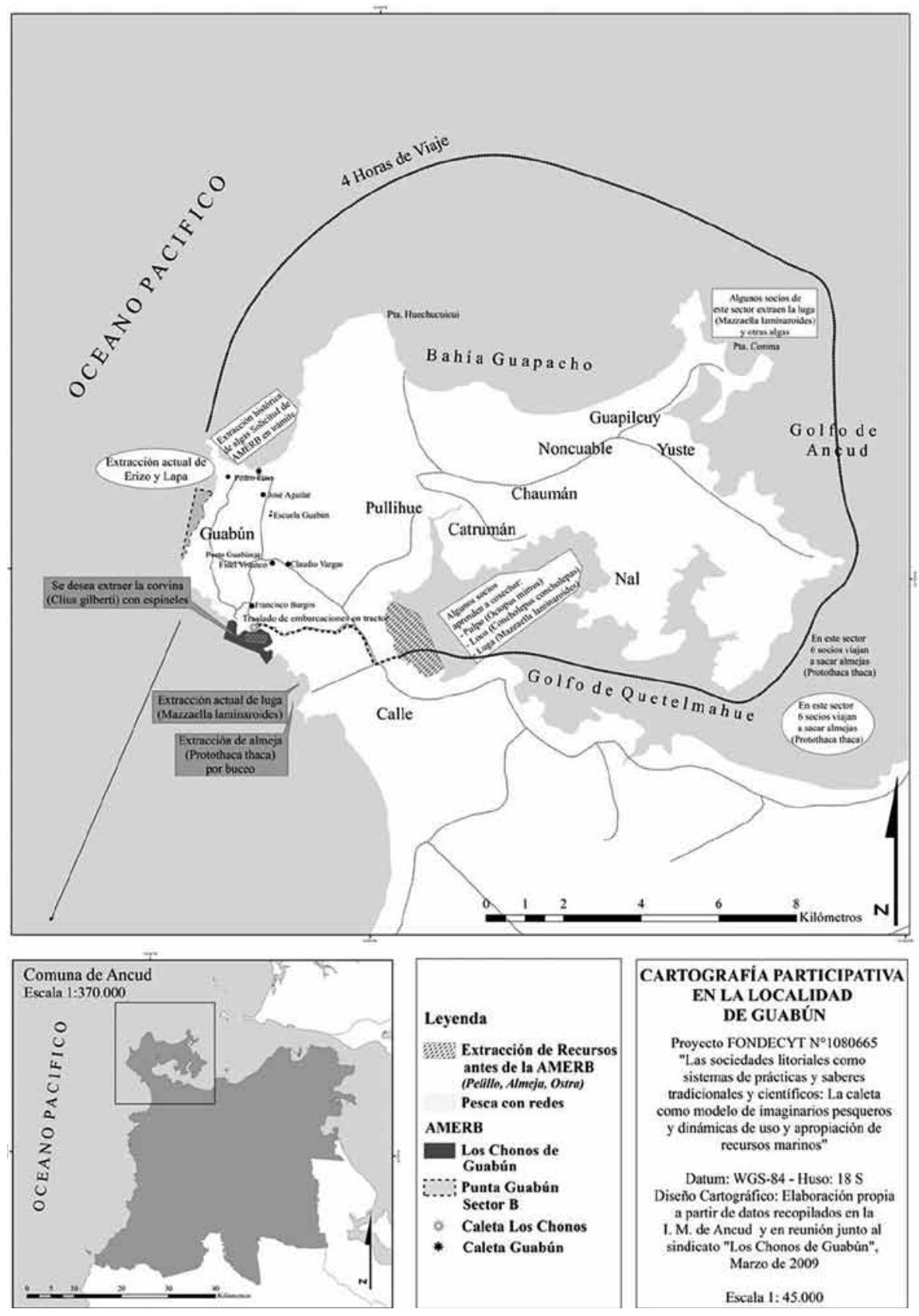

Figura 4. Cartografía Participativa en la localidad de Guabún 
nuevamente, se repite la acción. La localidad presenta una fuerte organización sindical, con un total de 24 socios (entrevista con don Pedro Pino, caleta Los Chonos de Guabún, febrero 2009). Además de contar con un líder de características sociales (a diferencia de un líder que podría ser de carácter comercial), posee un marcado arraigo a las tradiciones chilotas que reflejan una repercusión de conocimientos transmitidos de generación en generación (entre ellas destacan las mingas de papa y el trabajo agrícola ejercido con herramientas propias de la tradición histórica). Las prácticas sobre el territorio son ejercidas principalmente por la organización de pescadores. A su vez, las relaciones que esta unidad mantiene incluyen vínculos de reciprocidad en redes de apoyo, donde, por ejemplo, existen criterios compartidos para dar ayuda a algún miembro por situaciones de salud. Por otra parte, no todos los miembros del sindicato poseen una embarcación propia, es así como se distribuyen en las labores y costos, dedicándose en algunos casos solamente a bucear, otros a trabajar como asistentes del buzo y otros sólo manejan sus embarcaciones (patrón de embarcación). La segunda relación se zanja sobre un sistema jerárquico, el cual se impone sobre todo por razones funcionales. La autoridad de un jefe hace más eficaz la acción de un grupo, asegurando la cohesión de un gran número de sujetos. Esto fue fundamental al momento de crear un sindicato y lograr positivamente la tramitación legal para obtener el AMERB en el 2002, más aún cuando este jefe tiene un mayor conocimiento que el resto, en temas relacionados con el sindicalismo y los pasos necesarios para realizar una serie de acciones institucionales.

Las principales prácticas y saberes que modelan las dinámicas en este territorio costero-interior quedan definidas por la triada buceo/recolección/agricultura. Durante los últimos 30 años, los habitantes de Guabún han integrado estas tres dimensiones mediante diversas prácticas y técnicas. En particular el habitante de la caleta tiene un recuerdo vivo acerca del periodo en que aprendió a bucear. Este caso fue el episodio denominado «la fiebre del loco» (entrevista con don Francisco Burgos, sector Guabún, marzo 2009), generando una bonanza inesperada en aquellos años, además de la masiva llegada de buzos provenientes de todas las regiones del país en torno a la Isla Grande de Chiloé.

Desde mediados de los años noventa hasta el trabajo en el AMERB, esta localidad se ha mantenido en un constante auge, siendo la organización el principal gestor del desarrollo local. Históricamente se han utilizado para la extracción de recursos las mismas artes de pesca, destacándose el gancho de dos patas, una herramienta de hierro con mango de plástico cuyas terminaciones son dos 
puntas largas y curvas. Funciona cuando el mariscador coloca las dos puntas en un extremo de la concha (el extremo de su boca) y jala para soltarlo. El uso inapropiado de esta herramienta implica que la concha se afirme a la piedra tornándose imposible extraerla) y el chinguillo (un saco con textura de red en donde se depositan los recursos extraídos en el fondo marino), junto con el equipo de buceo (compresores y mangueras). El sistema de desembarque está muy influido por la geografía del lugar, cuya accesibilidad se hace difícil, además de no contar con vehículos adecuados para el transporte de sus productos (sistemas de frío, congelamiento y tamaño). En la mayoría de los casos, la transacción se realiza directamente en la playa, a través de intermediarios, figura determinante en la pesca artesanal, ya que a través de los costos del transporte logra incorporarse al proceso económico ligado al lugar de destino de los recursos extraídos, junto con representar un eslabón intermedio en la cadena productiva de la pesca artesanal en Chile. Existen condicionantes a las salidas de pesca, éstas se derivan de las intemperancias climáticas, que cíclicamente controlan las dinámicas intermareales. Las dinámicas territoriales se realizan entre los espacios del hogar, las playas y la costa marítima. En particular, estas dinámicas recorren las playas aledañas del lugar y cuidan el crecimiento y depósito de algas. Existen más de I 5 sectores identificados para la extracción de diversos recursos. Algunas playas corresponden a sectores apropiados por familias del sector de Guabún. La distribución de los sectores en las familias ha sido un proceso natural derivado de la cercanía de los asentamientos a las playas.

En este contexto, la figura administrativa (АMERB) es considerada como la principal fuente de ingresos en el año, la cual durante el periodo invernal se encuentra apta para extracción de loco, superando los Io cm (tamaño legalmente exigido). Es este el caso, donde el nivel de organización durante el año debe ser riguroso, entendiendo al AMERB como una réplica a la actividad agrícola, cuidando y monitoreando los cultivos constantemente. La asesoría técnica del cuidado y la cantidad de extracción, según lo exige la ley de Pesca, la realizan biólogos especializados, a los que el sindicato considera en un ítem de remuneraciones. Junto con esto aparece una nueva relación entre el espacio, localización y producción, lo cual sucede cuando se logra un nivel sustentable de productividad. A partir de esto el espacio pasa a ser deseado por otras localidades creando nuevos conflictos por el uso y usufructo del mismo. Es así como se recurre a sistemas de vigilancia armada, en donde han ocurrido asesinatos por parte de vigilantes en contra de buzos provenientes de otras caletas que lle- 
gan en las noches a extraer de manera clandestina estos recursos. El caso más reciente ocurrió en la localidad de Carelmapu, donde un vigilante dio muerte a un buzo que estaba sacando ilegalmente los recursos de un AMERB. Los periodos o faenas de trabajo no duran más de 5 días, entendiendo que en un lapso de 2 a 3 meses se trabaja esperando los días en que existan mejores condiciones intermareales, ya que durante esta fecha están influidos por el anticiclón del Pacífico y sus efectos en la dirección y velocidad del viento. Los ingresos son repartidos por igual, alcanzando a reunir un total de 2 millones de pesos por socio. La implementación del АMERB ha generado un mayor cuidado y comprensión de los recursos por parte de los habitantes de esta localidad, han aprendido a manejar un nivel de desarrollo local que sustenta sus necesidades y las proyecta al futuro, tanto así que ya se ha conseguido una nueva concesión para trabajar otros recursos (algas). Los procesos de apertura de mercados y reconversión productiva sufridos en este sector han calado profundamente el sistema productivo de sus habitantes, no obstante, las tradiciones y el arraigo por sus bienes y costumbres se ha mantenido, representando un ejemplo en relación con el contexto nacional de este tipo de política.

\section{Dinámicas territoriales y desarrollo de la diversidad local}

Las tensiones y separaciones implícitas en los mundos sociales de Guabún y Puñihuil implican una determinada actuación de las dinámicas territoriales en los espacios costeros. Para el caso de Puñihuil se trata de la fragmentación producida por las tensiones entre prácticas territoriales con orígenes nómadas y las prácticas territoriales que pretenden una apropiación sedentaria del espacio. En la caleta de Puñihuil, hay tres organizaciones sociales enfrentándose en torno al uso de los recursos. Dos de ellas se constituyen como organizaciones de turismo, en torno al uso de los islotes de pingüineras durante el verano. La tercera organización la constituye el sindicato de pescadores de Puñihuil, el cual se formó por el AMERB de locos. Este sindicato se caracteriza por su alta heterogeneidad interna, con miembros de otros lugares y de otras actividades. Tres elementos mueven y reconfiguran continuamente la estrategia de actores en este territorio: I) existe un grupo de pescadores provenientes del norte del país, que les interesó radicarse y convertir la caleta en su lugar permanente; 2) son miembros del sindicato por pago de derechos, pero no pescadores, sólo prefieren obtener las ganancias del AMERB verano a verano, incluso llegando a subcontratar para realizar sus trabajos; 3 ) existen tres restaurantes que pre- 
Tabla 1. Diferencias entre las caletas de Guabún y Puñihuil

\begin{tabular}{|c|c|c|}
\hline Variables & Puñihuil & Guabún \\
\hline Origen & $\begin{array}{l}\text { Presencia de pescadores nortinos } \\
\text { (cazadores por tradición) }\end{array}$ & $\begin{array}{l}\text { Presencia de una población } \\
\text { principalmente chilota }\end{array}$ \\
\hline Vivienda & $\begin{array}{l}\text { Asentamientos espontáneos fuera } \\
\text { del plan regulador }\end{array}$ & $\begin{array}{l}\text { Asentamientos incorporados al } \\
\text { plan regulador }\end{array}$ \\
\hline Modos de vida & $\begin{array}{l}\text { Desarraigo territorial, visión } \\
\text { economicista }\end{array}$ & $\begin{array}{c}\text { Arraigo territorial (costumbres y } \\
\text { tradiciones) }\end{array}$ \\
\hline Economía & $\begin{array}{l}\text { Turismo y pesca como la actividad } \\
\text { económica más lucrativa }\end{array}$ & Diversificación de actividades \\
\hline Institucional & $\begin{array}{l}\text { Instrumentos de administración } \\
\text { pesquera: AMERB }\end{array}$ & $\begin{array}{c}\text { Instrumentos de administración } \\
\text { pesquera: AMERB }\end{array}$ \\
\hline Estancia & Trabajo temporal en la localidad & $\begin{array}{c}\text { Trabajo durante todo el año en la } \\
\text { localidad }\end{array}$ \\
\hline
\end{tabular}

tenden completar sus paquetes turísticos de forma independiente. Estos tres elementos, han generado asociaciones y desorganizaciones de acuerdo a los problemas que se han planteado al territorio. Pueden agruparse transitoriamente, o establecer diálogos, pero no hay permanencia, sino más bien una alta efervescencia social, rápidos cambios y poca estabilidad (el representante que aunque no formal sino más bien natural del sindicato de pescadores es Juan Tomás Gonzáles). El segundo actor lo constituye una especie de instancia donde se organizan los restaurantes entre ellos y luego con los pescadores en torno al turismo existente (la persona que ha manifestado esta inquietud y propone un futuro integrador es Katja Siemund). Entre ambos es posible lograr confluencias, puesto que cada uno está, sin saberlo, dialogando con el otro. Por otro lado, el pescador está pensando a futuro integrar las prácticas de pesca con una fuerte actividad de turismo, mientras que Katja está proyectando una asociación con los pescadores en donde haya interconexiones beneficiosas para ambos sectores.

En Guabún, en la actualidad, la principal instancia de decisión lo constituye el sindicato de pescadores artesanales. Sin embargo, debido a que el sindicato es una unidad productiva orientada hacia el recurso loco, no es representativo de la comunidad en general, pues en Guabún existe además: I) una organización de mujeres que se dedica a la extracción de luga; 2) familias que no están incluidas en la producción de luga o el AMERB del loco que se sustentan de manera independiente en recolecciones de orilla y trabajos asalariados tran- 
sitorios. Existen en Guabún tres líderes constituidos de manera diferente por parte de la comunidad.

I. Don Pedro Pino, ha sido el gestor del amerb de locos en Guabún y representa la autoridad sindical. Ejerce también contactos comunicacionales con la radio y representantes políticos locales. Su legitimidad parece entroncarse con la de don Claudio Vargas. Sin embargo es su hijo quien lentamente está heredando legitimidad social y liderazgo.

2. Don Claudio Vargas, adquiere un progresivo aumento de responsabilidades en torno a la venta y vínculos comerciales. Representa la idea de emprendimiento en la comunidad y mantiene contactos con compradores y empresas locales.

3. La señora Genoveva Marisol, que ha adquirido responsabilidades respecto de proyectos con huertas y concesiones de algas, sus redes conectan la asociatividad entre las mujeres.

Considerando que en el pasado, los impulsos al desarrollo se han basado en la credibilidad de los jóvenes para con el presidente Pedro Pino y que su acción se ha basado en la existencia de un agente externo que ha promovido las acciones futuras, se considera dicha base de confianza. Para don Pedro el problema es la falta de asociatividad tanto entre pescadores como entre pescadores y agentes externos. Por ahí pasa la posibilidad del desarrollo; don Claudio, en cambio, estaría asociando la venta e incluso exportación de nuevos recursos, lo cual traería trabajo y, por ende, desarrollo. La señora Genoveva, admite la importancia de los cultivos y de las algas en la economía familiar y en pequeñas ventas que resultan ser muy significativas. En términos estratégicos, don Pedro Pino ejerce acciones de consejería con la señora Genoveva; desde sus relaciones familiares hay una confianza y jerarquía establecida, a su vez ella lo hace con otras mujeres. Juan Aedo posee también una legitimidad histórica, similar a la desarrollada con la consultora. Don Claudio, ejerce asesoría a los miembros del sindicato, lo cual resulta ser muy relevante. Las perspectivas de los actores se articularían en torno a proyectos de asociatividad entre pescadores que tengan relación con la producción de nuevas actividades productivas, que consideren prácticas de hombres y mujeres en el mar y también en tierra, no necesariamente identificados con procesos de tecnificación o modernización. Las divergencias entre actores se darían sobre prácticas no asociativas, sin relación con la producción de trabajos y que se 
especifiquen en sólo algunas actividades no considerando las de tierra y otras aparte del área de manejo.

\section{Discusión}

De acuerdo a los casos estudiados, vemos que para la comprensión de las dinámicas territoriales no es sólo importante conocer acerca del uso del mar y sus recursos o acerca de las actividades que allí se realizan, sino también se requiere conocer los principios operativos que explican la aparición, dinámicas y crisis a nivel local. El espacio litoral, en última instancia se muestra diverso ante el desarrollo económico que impera en los usos y actividades. Para el caso de Guabún vemos aquella manifestación de solidaridad ambiental y social, en el tiempo y en el espacio. En específico, las relaciones de solidaridad en Guabún muestran que a partir de las dinámicas territoriales es posible dilucidar principios de convivencia y territorialidad que aportan a repensar el desarrollo local. En el caso de Puñihuil, el desarraigo y la falta de conexiones internas muestran aquellos factores socioculturales importantes de considerar para entender las sociedades litorales. Mientras que para comprender que el éxito de las AMERB de Guabún es necesario partir por el arraigo que existe por parte de sus habitantes, que en el caso de Puñihuil aún se encuentra en una fase tardía, donde el fuerte interés por generar la mayor cantidad de recursos económicos posibles sin considerar lo que a su paso se ponga en frente puede explicarse por las características nómadas vinculadas históricamente a la pesca artesanal; más aún, el hecho de convivir estacionalmente en viviendas de paso, las cuales están dispersas en el borde costero, es otro indicador espacial visible de su naturaleza histórica-cultural.

Este modo de vida nómada ha encontrado conflictos directos con Guabún, lo que fue demostrado al conocer que en tan sólo 30 minutos de navegación desde Puñihuil se logra acceder a esta zona, la cual es visitada durante 20 días al mes (entrevista con don Juan Soto, caleta Puñihuil, febrero 2009). Es por esto que desde la caleta Los Chonos de Guabún se han implementado organizados sistemas de vigilancia armada, los que ya han conocido la presencia imprevista de buzos ajenos a su AMERB (entrevista con don Claudio Vargas, caleta Los Chonos de Guabún, marzo 2009). Otro problema que preocupa es la capacidad de carga y recuperación que puede presentar un ecosistema expuesto constantemente a presiones antrópicas; esto ha sido tratado por una serie de agrupaciones entre las que se destacan la fundación Ottway, Conaf y el Centro 
de Conservación Cetácea, estudiando directamente la situación que está sufriendo el monumento natural «Islotes de Puñihuil». Se han hecho intentos de capacitación a los habitantes de la caleta Puñihuil; ellos han entendido conceptualmente el asunto, sin embargo la falta de arraigo hace difícil el tratamiento de la situación como un potencial problema a tratar. Esto pasa a ser un desafío en la búsqueda por parte de las organizaciones más territorializadas que hacen latente una intervención en busca de un desarrollo local sustentable.

El estudio de las sociedades litorales y las dinámicas económicas ligadas a las figuras de administración pesquera poseen más de una concepción para ser tratadas, en el caso de la biología el tema ha ido en pos de un conocimiento estructurado de las funciones y el desempeño económico, cuando también deben ser consideradas las relaciones de parentesco, arraigo y asociatividad que trascienden al histórico pescador nómada y depredador incorporado a la reconocida cultura y tradición chilota. Es así como se hace indispensable incorporar la capacidad que tienen las ciencias sociales para tratar las problemáticas, escapando de la intransigencia y universalidad que en algunos casos se le atribuye a las ciencias exactas, incorporando grados de incertidumbre. Sólo de esta manera las investigaciones calarán en lo más esencial que busca el quehacer científico, el bienestar humano y social.

En vista a lo tratado en ambas localidades es posible teorizar que para entender un territorio es intrínsecamente necesario conocer las características socioculturales, tanto en sus formas, sus modos de vida como también los factores históricos que hacen de un emplazamiento un lugar económico y socialmente dinámico. Es así como en Puñihuil se observa el peso que tiene el interés económico influido por los históricos modos de vida que traen sus habitantes. En el caso de Guabún el desempeño sociocultural de sus actos está siempre presente en sus actividades. Así quedan sentadas las bases para que todo estudio de organización espacial en geografía, más aún en las ciencias sociales, sea considerado como un todo en las investigaciones de carácter cualitativo.

El tratamiento que aplican las ciencias sociales incorpora las relaciones que existen entre los seres humanos y el entorno es en este punto donde la geografía logra interceptar y aclarar las relaciones de espacio y poder, junto con argumentar metodologías aplicadas en contextos relacionados con el tratamiento de la información recopilada. «La concepción del espacio socialmente construido favorece una enriquecedora relación con la sociología, economía y política sin pretender el predominio de una disciplina sobre otra, en caso contrario demanda una buena formación epistemológica que permita 
realizar estudios transdisciplinarios que favorezcan el abordaje de un objeto de estudio complejo» (Rosales, en Lindon y Hiernaux, 2006). De esta manera no puede desligarse el aporte que desde las ciencias sociales ha tomado la geografía, no siendo suficiente con definir el espacio y las relaciones entre éste y el hombre, sino también haciéndose necesario evidenciar el entramado que articula el quehacer cotidiano de los modos de vida en las localidades estudiadas.

Desde este tipo de experiencias se abastecen desafíos que buscan abstraer los modos de vida capaces de explicar un modelo de organización espacial; sin embargo, el reto a lograr tal objetivo trasciende cuando se estudia la gran diversidad de formas de organización socioterritorial existentes en la articulación de cada localidad. Esto hace hincapié en generar nuevos estudios frente a realidades que se escapan del conocimiento científico tradicional, estando los actuales instrumentos, tanto administrativos como territoriales, constantemente cambiando, como consecuencia del impacto que ha generado la modernidad y a su vez la falta de investigaciones multidisciplinares que aporten con visiones holísticas a realidades particulares.

\section{Conclusiones}

La introducción en la economía internacional produjo cambios en las dimensiones ambientales y socioeconómicas de las caletas de pescadores artesanales. A ello se suma la creciente introducción de ciencia y tecnología que caracteriza el proceso de modernización de la pesca artesanal y un igualmente creciente proceso de oferta turística en zonas del litoral. Todos esos factores afectan el ordenamiento territorial y la administración de recursos costeros por parte de comunidades de pescadores.

Específicamente las transformaciones de la pesca artesanal han afectado a las comunidades de pescadores alterando sus prácticas sobre el territorio en dos ámbitos: mediante los efectos del mercado que demanda mayor cantidad de recursos y mediante las normativas que restringen las actividades pesqueras.

Las AMERB se presentan como un caso ilustrativo para el estudio porque aglomeran problemáticas de ordenamiento territorial en tanto sector concesionado a la organización y a la administración de recursos y en tanto que los pescadores deben decidir junto a un organismo técnico sobre las cantidades que extraer. Las dinámicas territoriales de los asentamientos costeros de Chiloé muestran que es posible avanzar hacia la diversidad de conductas y expre- 
siones socioculturales en cada asentamiento litoral. Dichas manifestaciones se expresan en el uso de la figura administrativa del área de manejo.

El arraigo territorial en un caso se presenta como un factor favorable al uso de las AMERB, mientras que la lógica nómade y el desarraigo se presentan como negatividades a la hora de formular estrategias de planificación local. Sin embargo, la diversidad es posible de gestionar mediante la estrategia de actores, en donde a partir de intereses comunes se logra esbozar la existencia de aspiraciones locales de desarrollo propios de cada asentamiento costero.

\section{Referencias}

Aliste, E. (2008). Aspectos sociales y culturales del desarrollo local: desafíos en la planificación y gestión ambientalmente sustentable del territorio. En A. Fuertes y L. Gatica (eds.), De la economía global al desarrollo local. El alcance de la intervención de los agentes de empleo y desarrollo local (8595). Valencia: Universidad de Valencia.

Andrade, B., Arenas, F., y Gujón, R. (2008). Revisión crítica del marco institucional y legal chileno de ordenamiento territorial: el caso de la zona costera. Revista de Geografía Norte Grande, 4I: 23-48.

Andriguetto-Filho, J. M. (I999). Sistemas técnicos de pesca y sus dinámicas de tranformación en el litoral de Paraná, Brasil. Tesis Doctoral, Universidad Federal de Paraná, Curitiba.

Arenas, F., Andrade, B, y Quense, J. (200I). La valorización de un espacio periférico: El caso de la costa oriental de la Isla Grande de Chiloé. Revista Norte Grande, 28: 79-90.

Arenas, F., y CÁceres, G. (200I). Ordenamiento del territorio en Chile: desafíos y urgencias para el tercer milenio. Santiago: Ediciones Universidad Católica de Chile.

Armada de Chile. (2008). Ley General de Pesca y Acuicultura. Ley nro. I 8.494 y sus modificaciones (I99I).

Ávalos Pino, P. (2006). Los impactos socioespaciales en las caletas de pescadores artesanales de la comuna de corral en el marco de la legislación pesquera promulgada entre los años I990-2005. Memoria para optar al título profesional de Geógrafo, Universidad de Chile, Escuela de Geografía, Santiago.

Ballesteros, X. (2006). Apuntes etnograficos del estudio de la cultura politica. En A. Higuera (coord.), Trabajo de campo: la antropología en acción (27-43). México DF: Plaza y Valdez. 
Barragán, J. (1997). Medio ambiente y desarrollo en las áreas litorales. Guía práctica para la planificación y gestión integradas. Barcelona: Oikos Tau.

Barragán, J. M., Alvarado, C., y Castro, C. (2005). Hacia la gestión integrada de las zonas costeras en Chile. En J. M. Barragán Muñoz, La gestión de áreas litorales en España y Latinoamérica. Cadiz: Universidad de Cádiz.

Bravo SÁNCHEZ, J. M. (2004). La cultura chilota y su expresión territorial en el contexto de la globalización de la economía. Memoria para optar al Título Profesional de Geógrafo, Universidad de Chile, Escuela de Geografía, Santiago.

Camus, P., y Hajek, E. (1998). Historia ambiental de Chile. Santiago: Pontificia Universidad Católica de Chile.

Carenzo, N. (2007). Territorio, identidades y consumo. Reflexiones en torno a la construccion de nuevos paradigmas en el desarrollo. Cuadernos de Antropologia Social, 26: I25-I43.

Centro de Conservación Cetácea (2007). Informe anual. Disponible en $<$ http://www.ccc-chile.org/docList.php?areaID $=80 \&$ cPath $=80>$.

Ceballos Cardona, M. (2009). Análisis de la ocupación territorial y manejo de algas en las caletas de Guabún y Pupelde incorporando los saberes tradicionales. Comuna de Ancud, Región de Los Lagos. Memoria para optar al Título de Geógrafo, Universidad de Chile, Escuela de Geografía, Santiago.

Confepach. (2008). Documento de propuesta entregado a la Presidenta Michelle Bachelet por Cinfepach. Recuperado el ro de enero de 2010 , de Federación Iterregional de Pescadores Artesanales del Sur: <www.fipasur.cl>.

Confederación Nacional de Pescadores Artesanales. (2007) Propuesta Ley de Pesca de la Confederación Nacional de Pescadores Artesanales de Chile. Disponible en <http://www.conapach.cl/>.

Cox Fernández, M. I. (2007). Plan integral de conservación y desarrollo, zona sur de la Cordillera de Piuchén, Chiloé: una propuesta de desarrollo participativo. Tesis para optar al título de Antropólogo, y al Grado de Licenciado en Antropología, Universidad Austral de Chile, Escuela de Antropología, Valdivia.

Couyoumdjian, J. R. (2009). El mar y el paladar. El consumo de pescados y mariscos en Chile desde la Independencia hasta 1930. Historia, 42 (I): 57-107.

Curumilla, S. (2006). Pueden perder pan y pedazo. Diario La Estrella de Chiloé, 4 de enero.

-. (2006). Puñihuil: zona de pingüinos y conflicto. Disponible en: $<$ http://www. 
laestrellachiloe.cl/prontus4_nots/antialone.html?page=http://www.laestrellachiloe.cl/prontus4_nots/site/artic/20060I04/pags/20060I040302 I 6 . html>.

Chambers, R. (2005). Participatory Mapping and Geographic Information Systems: Whose Map? Who is Empowered An Who Gains And Who Loses. Disponible en <http://www.ejisdc.org/ojs2/index.php/ejisdc/article/ view/238>.

Chandía, P. (2008). Factores socioculturales que influyen en el éxito de las AMERB en las caletas de Maitencillo y Horcón, v región. Memoria de para optar al título de Agrónomo. Universidad de Chile, Escuela de Agronomía. DíAz, A. (2008). Procesos sociales y lógicas productivas en la relación entre pescadores artesanales, Estado y mercado. Tesis para optar al título de antropólogo y al grado de licenciado en Antropología, Universidad Austral de Chile, Escuela de Antropología, Valdivia.

FrezzA, L. (1988). Actividad pesquera artesanal en las caletas de la v región. Caso de estudio: caleta Quintay. Memoria para optar al título profesional de Geógrafo, Universidad de Chile, Facultad de Aquitectura y Urbanismo, Santiago.

Gajardo, C., y Ther Ríos, F. (20I I). Saberes y prácticas pesquero-artesanales. Cotidianidad y desarrollo en las caletas de Guabún y Puñihuil, provincia de Chiloé. Manuscrito en aceptado en revista Chungará.

García-Allut, A. (2003). La pesca artesanal, el cambio y la patrimonialización del conocimiento. PH: Boletín del Instituto Andaluz del Patrimonio Histórico, 44: 74-83.

Gobernación Provincial de Chiloé. (2004). Pingüineras de Puñihuil: el Chiloé por descubrir. Disponible en <http://www.chiloeweb.com/Datos/ Noticias/Noticias.asp?No_Id=2004I 4004>.

Gobierno de Chile, Conaf. (2003). Monumentos naturales. Disponible en $<$ http://www.conaf.cl/?seccion_id=7eIoc398248909988d306eI I 487 e 5360 \&unid>.

Gobierno de Chile, Servicio Nacional de Pesca. (2007). Ley General de Pesca y Acuicultura. Disponible en <http://www.sernapesca.cl/index. php? option=com_remository \&Itemid $=246 \&$ func $=$ fileinfo\&id $=42>$.

Gobierno de Chile, Servicio Nacional de Pesca. (2007). Pesca artesanal. Disponible en <http:/www.sernapesca.cl/index.php?option=com_content \&task $=$ view \&id $=83$ \&Itemid $=220>$.

Gobierno de Chile, Subdere. (200I). Estrategia de Desarrollo Regional, 
Región de Los Lagos 2000-2010. Disponible en <http://www.subdere.gov. cl/I 5 Io/articles-66692_recurso_I.pdf>.

Grenier, P. (1984). Chiloë et les chilotes. Marginalité et dépendance en Patagonie Chilienne. París: Edisud.

Guerra, D., y Skewes, J. C. (2010). Acumulacion por desposesión y respuestas locales en el remodelaje de los paisajes estuariales del Sur de Chile. Chungara, $45 \mathrm{I}-465$.

Henríquez GenotTi, R. E. (2010). Lesgislación pesquera y paisaje litoral: los pescadores artesanales de la localidad de Pucatrihue, comuna de San Juan de la Costa, Chile. Tesis para optar al grado de licenciado en Antropología y al título de Antropólogo, Universidad Austral de Chile, Escuela de Antropología, Valdivia.

Hucke-Gaete, R. (2009a). Investigacion para el desarrollo del área marina costera protegida Chiloé. Primer informe de avance. BIP nro. 300402 I 5-O, Gobierno Regional de los Lagos, Conama, Universidad Austral de Chile.

- (2009b). Investigacion para el desarrollo del area marina costera protegida Chiloe. Segundo informe de avance. BIP nro. 300402 I 5-O, Gobierno Regional de los Lagos, Coaama, Universidad Austral de Chile.

Johnston, R. J, Gregory, D, Smith, D. (2000). Diccionario Akal de geografía humana. Madrid: Akal.

LEFF, E. (I994). Ciencias sociales y formación ambiental. Barcelona: Gedisa.

Lindon, A. (2007). Los imaginaros urbanos y el constructivismo geografico: los hologramas espaciales. Eure, 33 (99): 3 I-46.

Lindon, A., y Hiernaux, D. (2006). Tratado de geografía humana. Madrid: Anthropos.

Marino, C., y Bianchi, S. (I980). Chiloé: Cultura de la madera. Santiago.

Molinet, C., Arévalo, A., Díaz, M., y Díaz, P. (2008). Uso del borde costero en el mar interior de la región de Aysén y de Los Lagos: escalas e interacción de los procesos de pesca y acuicultura. En A. Lovatelli, A. Farías y I. Uriarte, Estado actual del cultivo y manejo de moluscos bivalvos y su proyección futura: factores que afectan su sustentabilidad en América Latina. Taller Tecnico Regional de la FAO, 20-24 de agosto del 2007 (237-247). Puerto Montt, Chile: FAO. Actas de Pesca y Acuicultura, nro. I2, Roma.

Montañez, G., y Delgado, O. (I998). Espacio, territorio y región: conceptos básicos para un proyecto nacional. Cuadernos de Geografía, (I-2): I-I6. MOP. (2006). Plan Nacional de Infraestrcutrua y Mejoramiento del Borde Cos- 
tero. Gobierno de Chile, Direccion de Planeamiento-Direccion de Obras Portuarias, Santiago.

Moreno, C. (2006). Conservacion de recursos costeros. En G. d. Chile, Conservacion de la biodiversidad de importancia mundial a lo largo de la costa chilena (98-100). Santiago: Ocho Libros.

Morin, E. (2008). Racionalidad y racionalidades. Quaderns de la Mediterrània, 303-305.

Negrón, J. (I992). La papa chilota. En D. Montiel, Chiloé a 500 años (IOII07). Santiago: Editorial Andes.

Pulido-Rodríguez, R., Ballén-Ariza, M., y Zúñiga-López, F. (2007). Abordaje hermenéutico de la investigacion cualitativa. Teoría, procesos, técnicas. Medellín: Universidad de Colombia.

Ramírez, J., Tapia, M. y Daiber, I. (2008). Propuesta de ordenamiento territorial, playa Puñihuil, comuna de Ancud, región de Los Lagos, Chile. Propuesta preparada para el Centro de Conservación Cetácea en el marco del Proyecto Alfaguara. Santiago Chile.

Retamales, P., y Álamos, I. (20I0). Distintas formas de trabajar un mismo mar. Una visión etnográfica de los pescadores artesanales desde Punta Teatinos a Tongoy. En F. Fuentes, M. Biskupovic, J. Castelleti y M. Retamales, Tradiciones de tierra y mar. Antiguos pescadores, mariscadores y cazadores del semiárido (I 7-45). Santiago: Fondo Nacional de la Cultura y las Artes.

Reyes, B., y JarA, D. (2005). Boletín intercambios nro. 49, del Centro Latinoamericano para el Desarrollo Rural: <http://www.rimisp.org/boletines/ bol 49 /INTERCAMBIOS\% 20N\%BA\% 2049\% 20Abril.pdf>.

RoJAs, J. (2004). Ordenamiento territorial: regiones activas y capacidades locales. Santiago: Escaparate.

SaAvedra, G. (2008). Desarrollo endógeno y dinámicas de significación cultural en el borde costero del sur austral chileno. Simposio de Antropología y cooperación al Desarrollo. España.

SANTANA, R. (I998). La papa chilota como patrimonio cultural. Líder, I-I3.

Santos, M. (2004). Por otra globalización: del pensamiento único a la conciencia universal. Bogotá: Convenio Andrés Bello.

SII. (2009). Dólar. <http://www.sii.cl/pagina/valores/dolar/dolar2009.htm>.

STOTZ, W. (I997). Las áreas de manejo en la ley de pesca y acuicultura: primeras experiencias evaluación de la utilidad de esta herramienta para el recurso loco. Estudios Oceanológicos, 16: 67-86. 
Tamayo Quilodrán, M. A. (2007). Reconstrucción histórica de las estrategias adaptativas en comunidades de pescadores artesanales. Dos casos en la décima región, provincia de Chiloé. Tesis de grado para optar al títilo de Antropólogo y el grado de Licenciado en Antropología, Universidad Austral de Chile, Escuela de Antropología, Valdivia.

TAYlor, S., y Bogdan, R. (I998). Introduccion a los métodos cualitativos de informacion. Buenos Aires: Paidós.

Ther Ríos, F. (comp.) (2003). Niveles y perspectivas de investigación en ciencias sociales. Diseños investigativos. Ceder, Universidad De Los Lagos, Osorno. Chile.

Ther Ríos, F. (2006). Complejidad territorial y sustentabilidad: notas para una epistemología de los estudios territoriales. Horizontes antropológicos, 25: I05-II5.

-. (2008). Prácticas cotidianas e imaginarios en sociedades litorales. El sector de Cucao, Isla Grande de Chiloé. Chungará, 40 (I): 67-80.

-. (2010). Construcción de imágenes e imaginarios litorales. En Enrique Aliste y Anais Urquiza (editores), Medio ambiente y sociedad. Conceptos, metodologías y experiencias desde las ciencias sociales y humanas (I 57-I76). Santiago: Universidad de Chile y Ril Editores.

-. (20II). Antropología del territorio. Manuscrito sin publicar.

Valles, M. (1997). Técnicas cualitativas de investigacion social. Reflexion metodologica y práctica profesional. Madrid: Síntesis.

Zamora, J., Barril, M. E., y Benavides, E. (20Io). Identificación de las barreras endógenas percibidas al desarrollo turístico de sol y playa. Estudios y Perspectivas en Turismo, 19: 22 I-240.

\section{Sobre los autores}

Francisco Ther Ríos es antropólogo, docente e investigador del Centro de Estudios del Desarrollo Local y Regional de la Universidad de Los Lagos. Su email es <fther@ulagos.cl>. Jaime Valderrama Bravo es geógrafo. Su email es<valderrama.jaime@gmail.com>. Este trabajo es resultado del Proyecto Fondecyt nro. I080665 «Las sociedades litorales como sistemas de prácticas y saberes tradicionales y científicos: la caleta como modelo de imaginarios pesqueros y dinámicas de uso y apropiación de recursos marinos». 